\title{
Integration of Lean Management Methods in Construction and the Building Information Modelling
}

\author{
Alexey Bulgakov ${ }^{1, *}$ and Thomas Bock $^{2}$ \\ ${ }^{1}$ Southwest State University, Department for Construction Management, 305040 Kursk, Russia \\ ${ }^{2}$ Technical University of Munich, Department for Building Realisation and Robotics, 80333 Munich, \\ Germany
}

\begin{abstract}
The article is devoted to the analysis of the application of lean production methods in construction with the account of modern advances in information technology. Well-known lean manufacturing approaches integrate BIM and Internet protocols. This allows you to optimize both the design and performance phases of construction work, which contributes to the highest satisfaction of the customer's needs.
\end{abstract}

\section{Introduction}

Lean Management in Construction (LC) aims to better serve the customer needs while requiring less of everything. In contrast to today's practice, Lean Management in the construction industry, however, relies on the principles of production management. The result is a project execution system that can be applied to any type of site design, but is particularly suited for complex, uncertain and fast projects.

Economic progress in the construction industry has not been able to compete with other key economic sectors for the last 60 years. This is mainly due to the lack of up-to-date production management with the pillars of "early cooperative cooperation between project participants" and "integrated digital modelling from planning to operation" as a tool for "continuous improvement of processes by avoiding waste" [1,2].

The Lean Management approach in construction provides an internationally proven approach for more cost-effective and cooperative execution of construction projects. LC is the adaptation of the universal management philosophy Lean Thinking to the construction industry. Its overarching goal is to create customer satisfaction through the greatest possible added value by eliminating waste (e.g. waiting times, excessive storage volumes, unnecessary transports, rework, etc.) are systematically searched for and eliminated. To this end, the builder, planner and construction contractor work as early as possible together on the planning of the building and the associated detailed workflows. During planning and construction, the contractors use the Last-Planner-System ${ }^{\text {TM }}$ to coordinate the processes together. Increases in productivity are achieved, in particular, through the stabilization of processes, that is, by minimizing disruptions in work performance. The logistical approach

* Corresponding author: a.bulgakow@gmx.de 
of the pull principle involves the timely delivery of materials and information at low inventory, controlled by the work at the end of the sequencers. The continuity of the work processes and the pull principle together form the core, the "flow" in the production system.

LC's collaborative approach is fueled by new forms of contracting and supported by the Building Information Modeling (BIM) IT approach, which enables end-to-end digital modeling of geometry, costs and deadlines from design to building operation. Internationally, numerous major projects have already been realized successful with LC, for example the largest freestanding building in the UK, Terminal 5 of the London Heathrow Airport (Fig. 1).

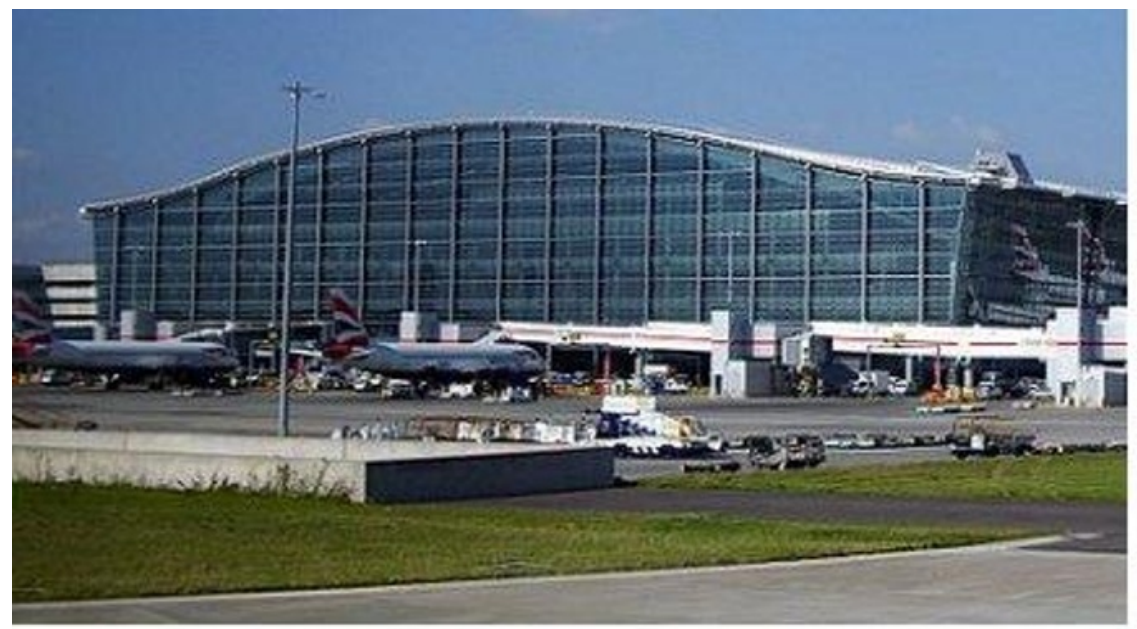

Fig. 1. Terminal 5 of London Heathrow airport

Waste, though not always obvious, is present in all processes. The goal of Lean Management is to create value without waste, with the highest quality of products, lowest cost and short delivery time. In the early 1990s, Womack, Jones \& Roos described in their book "The Second Revolution of the Automotive Industry" the principles of lean production, which can be traced back to Toyota's production system:

- Define the value from the customer's perspective

- Identify the value stream

- Implement the flow principle

- Introduce the pull principle

- Strive for perfection

At the heart of Lean philosophy is the customer, who defines the value to be created. Thus, especially in the construction industry, the exploration of values is an important part of the work of the project team. Within the team, there is transparency about performance and responsibility as well as personal responsibility and appreciation of all employees. Therefore, the introduction of lean management usually requires a change in the corporate culture. With the implementation of the principles and the transformation of the environment can be continuous improvement sustainable, which is the core of avoiding waste $[3,4,5,6]$.

\section{Basics of Lean Construction}

Lean management system consists of a number of tools, but in particular of fundamental approaches and philosophies. It is also a living system that is constantly evolving. 
The reliability of the workflow can be significantly improved by removing the variations and uncertainties from the system. You have to connect your own production system with every product development, this means optimal product and optimal production belong together and are defined in a workflow simultaneously and not consecutively. That does not mean that the old and the successful are thrown overboard. It just means that everything is questioned and focused on the particular work situation, the product and its manufacturing process, and the intermediate and end customer.

Any type of buffer and temporary storage and inventory is defined as waste. Waste because these materials are held up only because the process is unstable and not consistent in all stages of production and reliable flows. In this continuous flow, there is the greatest potential to increase the productivity and effectiveness of the process. The stocks are to be reduced radically, even if this only occurred production stoppages. You accept it to see "where it is stuck". It is called: lowering the water level to make visible the cliffs over which the production ship sails, and thus make it degradable $[7,8,9,10]$.

A lean manager will not only correct the actions, but also analyze the baseline situation and incorporate the basic observations into the correction cycle. So in order to do that, we need a new perspective and, ultimately, a new generation of managers who are capable and based on experience and the tools provided in lean management, of course, the basic things in question to make the project and the entire environment and also organizations to redesign again.

LC is a production planning and control system that encourages all stakeholders and stakeholders to work together actively to create a process with higher productivity and, above all, a dependable workflow. This set of tools includes the Lean Project Delivery System (LPDS).

Other approaches to improvement include increasing predictive confidence, as smaller and smaller time periods are used for planning: from the week to the day, to the hour. The control frequency must be carried out in the same rhythms and then very quickly leads to concrete approaches to improvement, because every non-fulfillment of a prediction is subjected to an analysis and the improvement measures are initiated. This is the direct entry into continuous improvement processes (CIP), a classic element of lean production (Fig. 2).

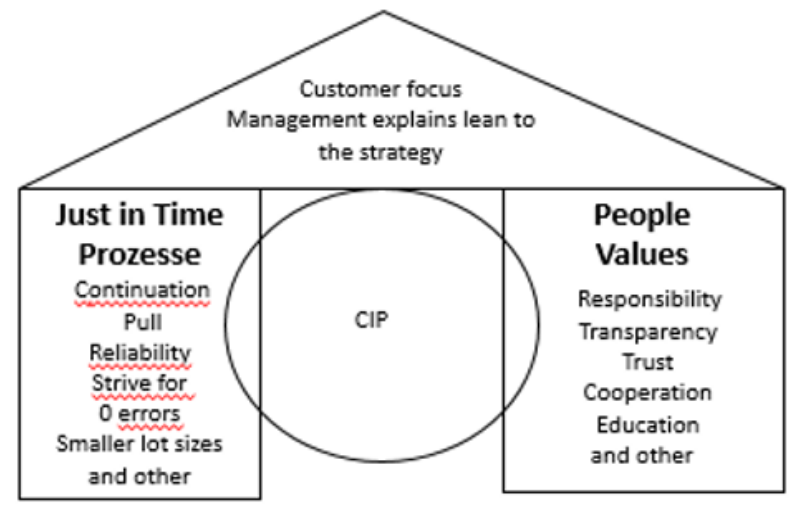

Fig. 2. Lean house

Supporting these processes, it is already possible today to use software that has been specially developed for construction or project-typical companies, the SPS / PM software.

The continuity of the work flow and the reduction of unnecessary intermediate storage according to the pull principle are essential components in all of the aforementioned building-specific application methods of lean construction. 
The just-in-time principle is not the starting point but the result of a long development that focuses on improving processes. In the processes unnecessary waiting times, queues, warehouses to stabilize production were identified and ultimately identified as waste. It has also been found that these wastes are very much related to the discontinuity of the material and information flow (buffers to compensate for the fluctuations). In order to reduce or eliminate these wastes, it was therefore necessary to stabilize the processes and bring them into a uniform flow. From this developed the principle of the uniform work flow, which allowed to reduce unnecessary buffers, interim storage and other wastes.

The ultimate goal of every planning and business is the customer. He is thus the trigger of the pull principle (Fig. 3). The customer-oriented pull principle ensures that in each

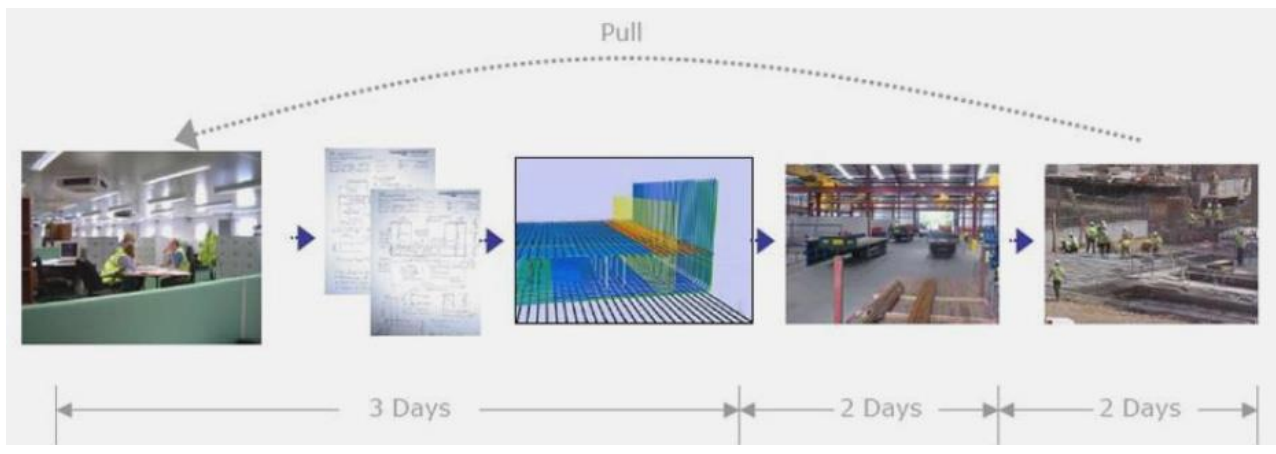

Fig. 3. Pull principle

workstation only that which really benefits the next processor is produced. Anything that does not benefit this benefit is a waste.

\section{Last Planner System}

With regard to the client's claims for defects, differences to the traditional construction contract could arise insofar as the client and the contractor were equally involved in the planning. Therefore, it makes sense, the inspection and notification obligations in the context to regulate the Last Planner System (LPS) in detail.

Behind the system of the Last Planner is the idea that in the case of complex projects it is not possible to provide construction planners months in advance with detailed construction planning, which will then be adhered to with the given deadlines and costs. Instead of a consecutive hierarchical construction plan, which is developed by a general planner and then contracted and "blindly" given to the participants, the Last Planner System TM involves a cooperative integration of the construction participants already in the planning phase. Instead of planning in the long term in the same way as in traditional project management, it is checked for the following week whether tasks can actually be carried out, as well whether the prerequisites for execution are met. In retrospect, traditional project management responds to errors as soon as a planned activity could not be carried out. The Last Planner system checks in advance whether an activity can actually be carried out. If this is not the case, a buffer of tasks is used whose executability which are not timecritical, that is flexible in the timetable without impact on the critical path. Since the tasks are flexibly awarded according to their feasibility, changes in the project (for example on the construction site due to bad weather or non-existent material) can be directly reacted to, and the workforce is well utilized despite uncertainties and change [11,12]. 
The LPS is divided into five phases:

1. Frame schedule.

The basis of the planning is the classic frame schedule with the most important milestones of the project. It is the starting point for the cooperating phase deadline.

2. Cooperative phase deadline.

By sticking on dependent "post-its" becomes a part or the whole Framework schedule chart visualized in the project management team. The individual activities will be set by the participants themselves in the best possible order, and the dependencies between the activities, that is, what conditions for carrying out an activity have to be created, become clear. By integrating the expertise of the Last-Planner increases the probability of all dependencies in complex planning and to recognize the building process. Furthermore, take for the individual activities established. By trusting in the team, the traditionally often scheduled buffers for Securing the unreliability of previous activities. The saved Time is sometimes used to work together as a buffer for the entire process determine where it makes sense for the whole process. Overall, it shortens thus the project duration.

3. Preview planning.

At regular intervals, such as weekly load planner sessions, The activities developed by the cooperating phase scheduling are teamed on expected obstacles and missing prerequisites. This can be done through The list of activities and known obstacles in Excel lists are supported. The elimination of known obstacles is queried and the addition of new ones Obstacles checked. The obstacle-free activities from the preliminary planning are the starting point for the detailed planning.

4. Detailed planning (daily planning).

The detailed planning lists the obstacle-free activities. If the performer At the same time, he gives responsibility to an activity that promises to carry it out for the evaluation in the fifth phase by the PEA value. So he has one Interest to point out from the outset all obstacles to the execution of "his" activity.

5. Evaluate, Learn and Improve.

In the fifth phase, the Lean principle of continuous improvement is implemented. The commitments made at the last meeting will be reviewed and the reasons for noncompliance with so the non-execution of planned activities will be investigated. It makes sense to classify reasons for non-compliance. The performer of the activity is interviewed with the aim of finding the root of the problem to reoccur to prevent the same problem. The learning processes in the project avoid mistakes and the flow of production stabilizes.

The Last Planner system is the core of Lean Management in construction and thus the core of the project execution model, which this contract describes. Cooperation is a prerequisite for the use of the Last Planner system, because the contractors must use their resources flexibly, which may mean that they have to postpone their own interests (for example, the planned use of their workforce on another construction site). For complete cooperation, it is often necessary that even incomplete information be shared in the last load planner sessions, for example to alert you to potential risks. Also, the transfer of preliminary or incomplete information in the planning phase, for example, the sharing of proposed solutions, leads to a better workflow in the team. This is where the planners' liability limitation mechanism comes into play. In traditionally completed projects, the flow of information is hampered, as a transfer of provisional information can mean subsequent changes, which in turn can lead to complaints by an affected planner. However, if the provisional nature of the information in the handover, the efficiency of the planning can be 
significantly increased. By using the Last Planner system, significant improvements in resource utilization and construction time reductions were achieved.

In order to implement the principles of lean management in construction, new forms of contract are needed, which through coordination mechanisms provide incentives for the cooperation of project participants. This form of contract can be realized by creating a project environment through the implementation of cooperative measures, which can be more efficient application of Lean Management tools enabled and their application suggests almost. Whether the goals of keeping costs and time in the budget without sacrificing quality must be achieved in practice, by adopting lean management methods in a collaborative environment. With the implementation of these methods, however, a new "momentum" can be brought into existing contract models. In particular, the combination of successful contract elements and tools of both models can lead to a better utilization of resources in construction and also to an atmosphere of trust and cooperation. Ultimately, lean management is leading to a paradigm shift from focusing on the scope of performance obligations to focusing on the nature of cooperation.

\section{Lean Construction and Building Information Modelling}

Regardless of the developments in lean production and lean management in construction, computer techniques have been developed that can make planning more secure and also capable of mapping processes. Some have been around for quite some time, others have recently come to maturity. To this entire group is modeling to $3 \mathrm{D}, 4 \mathrm{D}$ (if the timeline is added) and 5D (if the cost side is still included). A very comprehensive instrument is the so-called BIM (Building Information Model). Here not only the geometric advantages of the $3 \mathrm{D}$ model are used, but all components contain all the information about the components [13]. This includes information about the way they are made, assembled and in what order (Fig. 4). This, of course, means that the integrated planning team has to

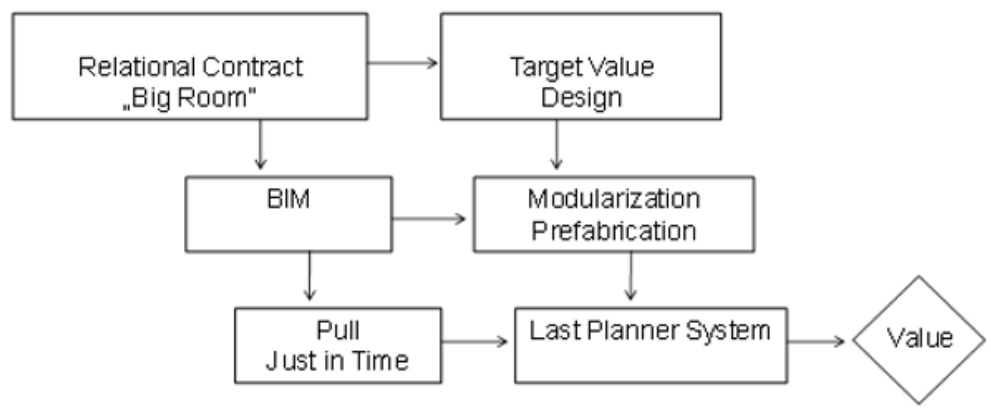

Fig. 4. Main components of Lean Construction

think hard about execution during the design, planning, and execution planning phases. This fulfills Lean's demand for a simultaneous design of the product and the process and is therefore demanded and promoted.

\section{Conclusions}

Each planning process is about predicting and planning the future. There is no question that several people can predict this future better than a few. In our planning reality, however, it looks like initially a planner or a small group is designing in a time phase where the cost impact is highest. Other planners and detailed planners and specialist planners and in 
particular construction companies and subcontractors are kept outside with their knowledge. If they were involved at an early stage, then together we could predict and shape the future much better (the best way to predict the future is to design it). This early cooperation is not allowed to happen simply because the few people who are in the team at the beginning are not confident that they will be able to select the partners for the upcoming forecasts at an early stage according to criteria that make it easier to deal with the future together. It is thought that the builders or the small start-up team are not sufficiently competent and trustworthy to make the choice of the other partners not only on cost comparison of offers. At the same time, however, one trusts this small starting team, yes even requires him to predict the future all alone (to plan). If the team is to do the latter, then one would also have to trust it to choose the other partners early on and according to a completely new set of criteria and values.

In lean management, everyone wins, except those who live off waste.

\section{References}

1. W.J. Hopp and M.L. Spearman, (1996). Factory Physics: Foundations of Manufacturing Management. Irwin/McGraw-Hill, Boston, Mass.

2. G. Ballard and G. Howell (1997). "Shielding Production: An Essential Step in Production Control." ASCE, J. of Constr. Engrg. and Mgmt., 124 (1) 11-17.

3. A. Hofackerю Bewertung und Einführung von Lean-Methoden in der Einzel- und Kleinserienfertigung am Beispiel des Stahlbaus. Dissertationsschrift. - Karlsruhe, 2010.

4. C. Reuter. Logistikrelevante Lösungen auf der Basis von Lean-Management bei kleinen Losgrößen und hoher Variantenvielfalt. Dissertationsschrift. - Stuttgart, 2009.

5. M. Sanchez, M. P., Perez. Lean Indicators and Manufacturing Strategies, International Journal of Operation and Production Management, 2001. 21:1433.

6. C. D. Ray, X. Zuo, J.H. Michael, J. H. Wiedenbeck, J. K. The Lean Index: Operational" Lean" Metrics for The Wood Products Industry, Wood and Fiber Science 2006; 38:238.

7. H. Soriano-Meier, P.L. Forrester. A Model for Evaluating the Degree of Leanness of Manufacturing Firms, Integrated Manufacturing Systems 2002; 13:104.

8. M. Eswaramoorthi, G. R. Kathiresan, P. S. S. Prasad, P. V. Mohanram. A Survey on Lean Practices In Indian Machine Tool Industries, International Journal of Advanced Manufacturing Technology 2011; 52:1091.

9. J. Metternich, S. Bechtloff, S. Seifermann, Efficiency and Economic Evaluation of Cellular Manufacturing to enable Lean Machining, Procedia CIRP 7 (2013) 592 - 597.

10. F. Guerriero, J. Miltenburg. The stochastic U-line balancing problem, Naval Research Logistics 50 (1) (2003) 31-57.

11. Y. Monden. Toyota Production System. Industrial Engineering and Management Press, Norcross, GA 1983.

12. C. Becker, A. Scholl, A survey on problems and methods in generalized assembly line balancing, European Journal of Operational Research168 (2006) 694-715.

13. A.H. Fakhimi, J. Majrouhi Sardroud and S. Azhar. How can Lean, IPA and BIM work together? // $33^{\text {rd }}$ International Symposium for Automation and Robotic in Construction (ISARC 2016). 